\title{
Central Park Squirrel Census Maps
}

\author{
Nathaniel Garnett Slaughter IV a, \\ a Chief Cartographer for the Squirrel Census, LLC, nathaniel@thesquirrelcensus.com
}

Keywords: New York City, Census Maps, Eastern Gray Squirrel

\begin{abstract}
:
In October of 2018, the first official squirrel census of New York City's Central Park was conducted. Throughout the project's 30-month duration, maps were a critical tool - from logistical planning and data gathering, to data analysis and presentation of census results. Of these project phases, two in particular generated important cartographical work, not only to the success of the census project, but within the historical lineage of Central Park maps: the Tally Map, which was used for squirrel and park data collection, and the series of maps to be used to present the census findings in the Official Central Park Squirrel Census Report.
\end{abstract}

For the census count, a highly detailed map of the park's 378 hectares was needed to help over 300 volunteer sighters navigate the park and accurately plot squirrel locations. A 16-month, iterative process of drawing and on-site verification has produced the most detailed map database of the park in the past 80 years. The Tally Map, one of the most detailed and substantial maps in the park's 160-year existence, measures 3 x 1.3 meters.

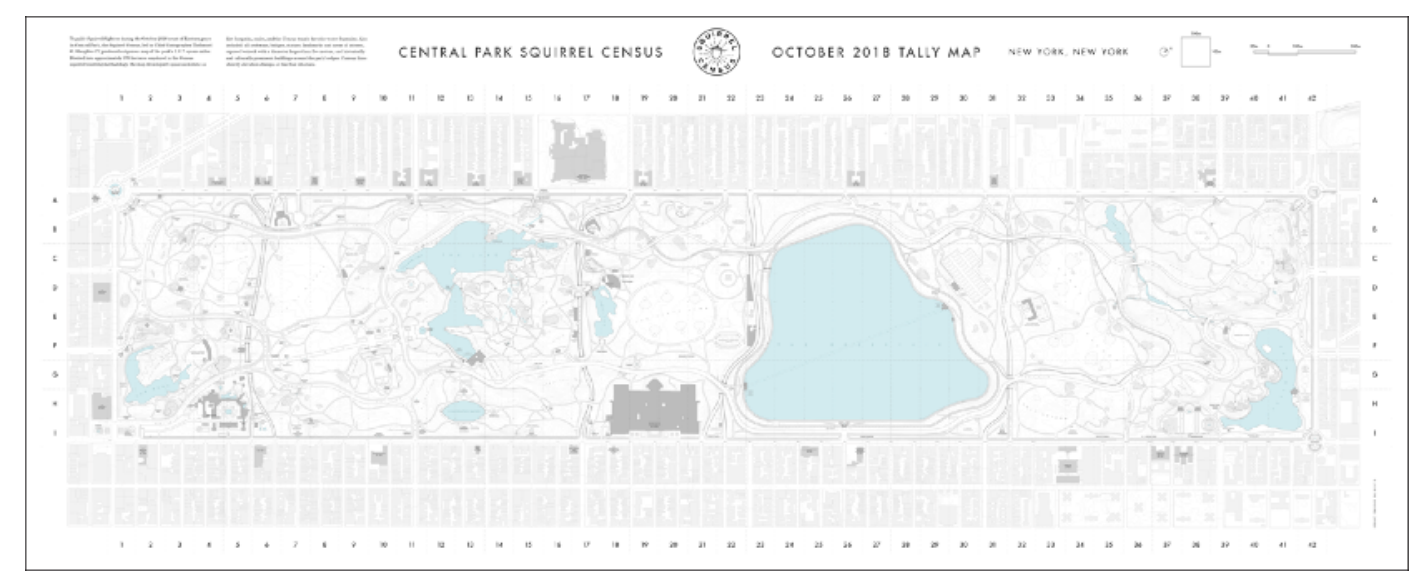

Figure 1. The Central Park Squirrel Census Tally Map, October 2018, 1:1875, 3 x 1.3m, digital inkjet plot

The Tally Map had three goals to meet. First, the map needed to perform as a navigation and way-finding tool. Census volunteers required a map to help navigate the thoughtfully designed sequence of park spaces, and find the general area of the hectares - the spatial unit used in the census count - they were assigned to count. Second, the map needed to have enough detail so that once volunteers have found their assigned hectare, they were able to establish hectare boundaries. Third, the map needed enough detail so that squirrel locations could be plotted on the map, with a relative accuracy that was deemed acceptable and reasonable.

The map making process began with an audit of existing Central Park construction documents, maps and surveys, and also an assessment of existing map data that was publicly accessible - NYC Open Data and Open Street Map (OSM).

Research into existing maps of Central Park provided a historical lineage the Census maps would acknowledge, respect and be a part of. This research along with the goals stated above established the design guidelines for Central Park Squirrel Census maps: 1) the map should be one of the most detailed and accurate maps in the park's history, 2) every line and line relationship should be drawn with geometric purity and precision, and 3) every map feature should not only be accurate and exhaustive in its information, but beautifully styled and depicted.

While the assessment of existing map data unveiled the ability to create detailed maps of Central Park, there were issues with the data that did not meet the established map design guidelines. The main issues were of accuracy and drawing quality. There were scores of areas that did not incorporate park enhancements and changes, thus not meeting the criteria of assisting volunteers with park navigation, and due to either LiDAR shadowing or data-processing margin of error, contour lines suggested inaccurate topographic conditions. There were also countless examples in every hectare of improper drawing, either produced by automated drawing processes or those like in OSM that are incredibly limited in their ability to draw curves or offset parallel lines. 
Due to these discrepancies between the project's design guidelines and the existing map data available, it was determined that a new map database was required - that the map would need to be drawn from scratch.

The process oscillated between drawing and map development, and visiting the park in order to verify drawings, take notes and sketch ground conditions. Adobe Illustrator was selected as a drawing application due to its ability to perform offset and array executions, ability to draw bezier curves, and was capable for working in sync with a map database in QGIS or by using the Map Publisher plugin.

The result is a map showing actual widths of the carriage roads, bridle and foot paths, and details that unveil the interwoven, vertical relationship of the park's three main circulation systems. Details show how path systems meet areas of interest and artificial features such as buildings and playgrounds. Distinction between foot path types are expressed for paved, maintained mulch paths and well-established desire-line dirt paths. All stairs have been mapped, as well as all light posts in forested areas and exposed bedrock with a diameter greater than five meters. All artificial features have been labelled, such as buildings, playgrounds and statues, as well as important historical sites.

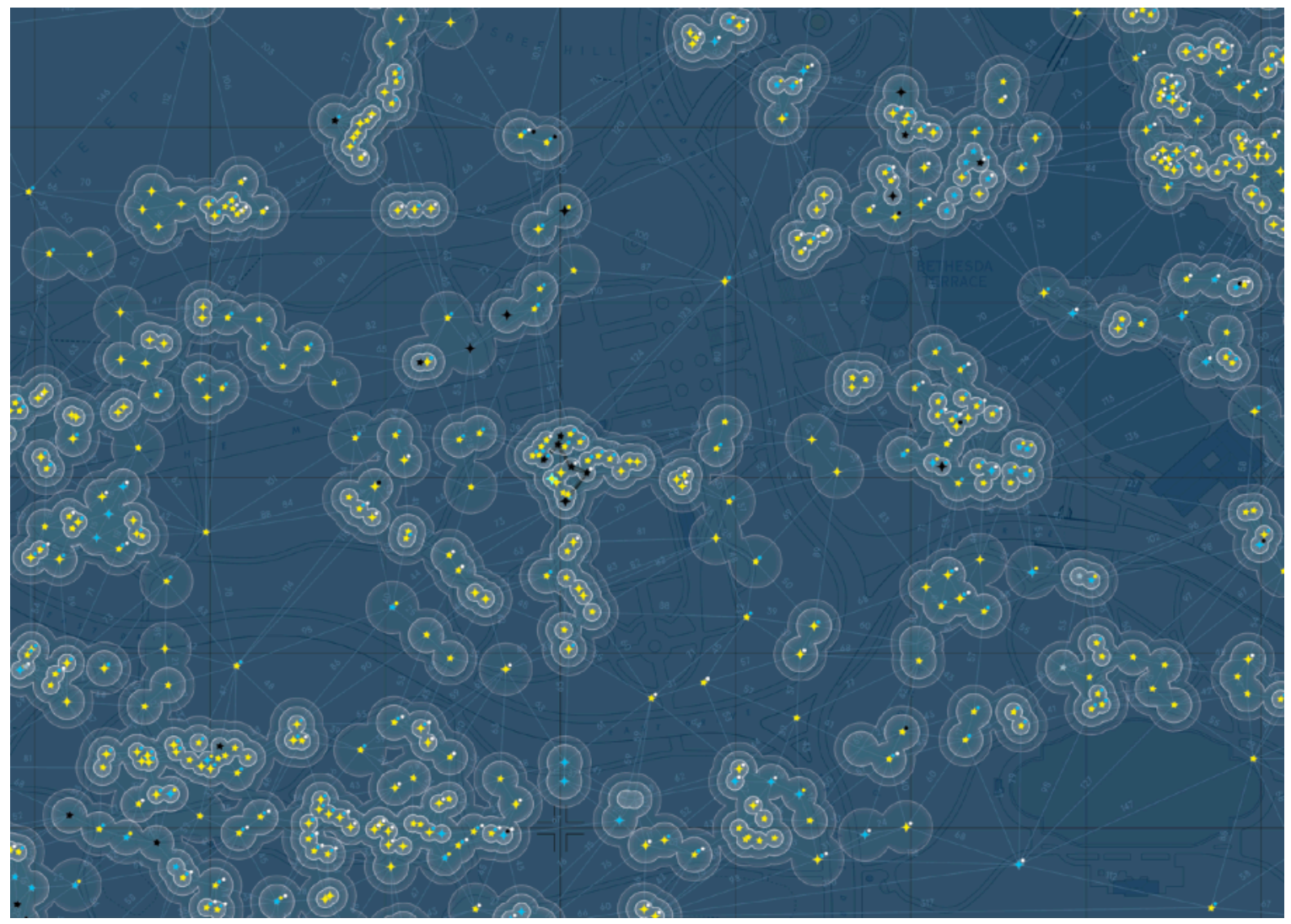

Figure 2. Map showing squirrel location, density and fur colorations, park detail of The Mall

The Tally Map's style is decidedly utilitarian with a desire to showcase its geometric purity and level of detail through a minimal and supportive stylistic language. It aims to assist the purposeful rambler in need of a specific hectare, and to provide for reference geographic and artificial features, as well as a comprehensive catalogue of labels.

For assisting the volunteers during the count, the Tally Map was formatted at two different scales for two of the map's primary goals. First, the map was scaled to 1:2500 to provide an "Area Map" of the park so volunteers could navigate the larger park area their assigned hectares exist, and to identify each assigned hectare's boundaries. A smaller scale map at 1:1250 provided 3"x3" "Hectare Maps" to further assist in identifying hectare boundaries and for volunteers to plot squirrel locations onto the map. Both the Area and Hectare maps were formatted and carefully designed along with the tally sheets for gathering data into a "tally sheet" package that was handed out on clipboards and pencils to each volunteer.

In January 2019, work on the Official Central Park Squirrel Census Report will begin, to be printed and released in June 2019. Similar to the previous two Squirrel Census Reports from other counts, the report will consist of various maps and charts. As of December 2018, the preliminary plans are to create, from the Tally Map, a 1:2500 map of Central Park showing squirrel locations and data, along with supporting park section drawings, charts and information, as well as an additional 1:2500 map with no squirrel data, for future park explorations for those who acquire a report. The report will also contain various auxiliary maps and charts that support and enhance the report's content and narratives. 